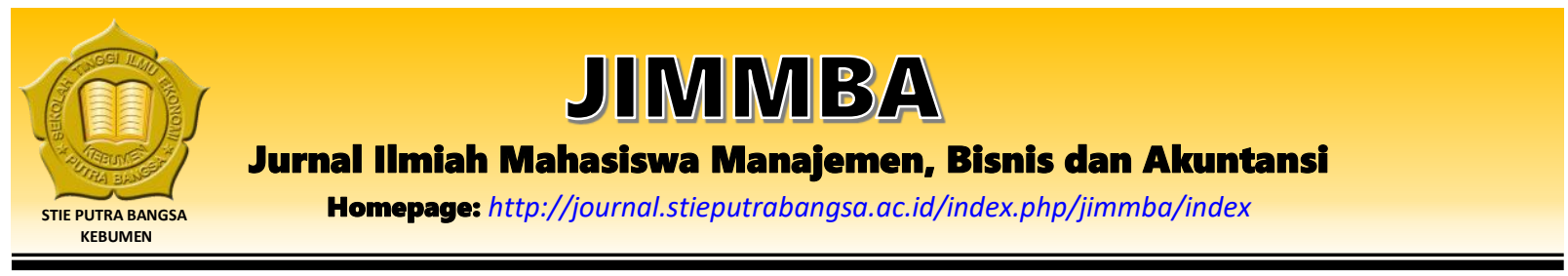

\title{
Pengaruh Workplace Spirituality dan Person Job Fit Terhadap Intention to Stay Melalui Organizational Commitment sebagai Variabel Intervening
} (Studi pada Pegawai LAZIS Al Ihsan Jawa Tengah)

\author{
Lukman Surantoro', Much. Riyadus Solichin ${ }^{2}$ \\ 1,2Sekolah Tinggi Ilmu Ekonomi Putra Bangsa \\ Email: lukmansurantoro98@gmail.com¹, riyad.kroya@gmail.com²
}

\section{ARTICLE INFO}

Article History:

Received: November $2^{\text {nd }} 2020$

Accepted: December 23 2020

Published: December $31^{\text {st }} 2020$

Keywords:

Workplace Spirituality,

Person Job Fit,

Organizational

Commitment, Intention to Stay

\begin{abstract}
Penelitian ini bertujuan untuk menganalisis pengaruh workplace spirituality dan person job fit terhadap intention to stay melalui organizational commitment pada pegawai LAZIS Al Ihsan Jawa Tengah. Pengumpulan data dilakukan dengan kuesioner, dengan menggunakan Skala Likert 4. Penelitian ini mengambil sampel 53 responden pada pegawai LAZIS Al Ihsan Jawa Tengah. Hipotesis diuji menggunakan program SPSS 25.00 for windows. Hasil penelitian menunjukkan bahwa workplace spirituality tidak berpengaruh signifikan terhadap organizational commitment. Person job fit berpengaruh signifikan terhadap organizational commitment. Workplace spirituality berpengaruh negatif dan signifikan terhadap intention to stay. Person job fit berpengaruh signifikan terhadap intention to stay. Organizational commitment berpengaruh signifikan terhadap intention to stay. Organizational Commitment memediasi variabel workplace spirituality terhadap intention to stay. Organizational commitment memediasi person job fit terhadap intention to stay.
\end{abstract}

\section{Pendahuluan}

Suatu ekosistem sebuah institusi maupun perusahaan pasti mempunyai dan membutuhkan sumber daya manusia sebagai salah satu faktor penentu kesuksesan suatu instansi atau perusahaan. Sumber daya manusia merupakan aspek krusial yang menentukan keefektifan suatu organisasi sehingga peran sumber daya manusia sangat penting bahkan tidak dapat diabaikan keberadaannya. Menurut Tepeci (dalam Ibrahim, 2016) mengatakan bahwa sebuah organisasi dapat berjalan efektif bila didukung oleh sumber daya manusia. Pernyataan tersebut menerangkan bahwa sebuah organisasi dapat mengalami pertumbuhan berkelanjutan tergantung pada bagaimana organisasi harus dapat mempertahankan karyawan yang dimiliki untuk dapat tetap bekerja sesuai dengan tuntutan yang ada.

Pada hakikatnya, sumber daya manusia terdiri dari dua hal yaitu daya fikir dan daya fisik. Kemampuan setiap manusia berasal dan ditentukan oleh dua hal tersebut yang direalisasikan menjadi performance. Kemampuan itu bersifat fleksibel karena dapat diupgrade dan juga terdowngrade. Hal itulah yang akan menjadi roda penggerak sebuah institusi atau perusahaan. Oleh karena itu, perusahaan atau institusi harus bisa mengelola dan mengembangkan sumber 
daya manusia yang dimiliki dengan baik agar skillnya meningkat sehingga tercipta sumber daya manusia yang kompeten.

Bagi suatu perusahaan atau instansi sudah sepantasnya memberi perhatian besar terhadap pengelolaan sumber daya manusia yang dimiliki. Dengan demikian perusahaan atau instansi dapat menghasilkan tenaga kerja yang berkualitas sehingga dapat membantu kelancaran kegiatan perusahaan atau instansi dalam mencapai tujuan. Di sisi lain, untuk memperoleh sumber daya manusia yang berkualitas dan mempertahankannya dalam jangka waktu panjang perlu upaya yang lebih maksimal. Kegagalan mengelola sumber daya manusia yang baik dalam suatu perusahaan atau instansi mengakibatkan kurangnya keinginan karyawan untuk tetap bertahan dalam perusahaan. Hal ini memungkinkan lahirnya suatu permasalahan baru yang sulit dihindarkan yaitu tingginya tingkat turnover. Turnover yang tinggi akan merugikan perusahaan, baik dari segi biaya, sumber daya, maupun motivasi karyawan.

Baru-baru ini, LAZIS Al Ihsan Jawa Tengah (Lazis Jateng) mendapat penghargaan bergengsi dalam Baznas Award 2019. LAZ dianugerahi sebagai Provinsi Kategori dengan Pendistribusian ZIS Terbaik. LAZ Al Ihsan Jawa Tengah juga masuk nominasi Kategori Kelembagaan Terbaik, Kategori Pertumbuhan Pengumpulan ZIS terbaik, Kategori Laporan Tahunan terbaik dan Kategori Program Pendayagunaan ZIS terbaik tingkat Nasional. Sayangnya, keberhasilan peningkatan kinerja organisasi tersebut masih memiliki beberapa permasalahan yang sering terjadi di lingkup manajemen organisasi, seperti intensitas turnover karyawan yang cukup tinggi, rendahnya intention to stay karyawan, manajemen administratif yang tidak teratur, evaluasi kinerja di beberapa cabang yang mengalami kendala dan kenyamanan kondisi spiritualitas di tempat kerja (ada kajian pekanan, kebebasan berkomunitas, dan saling menghargai sesama karyawan) serta kecocokan individu dengan pekerjaan karyawan.

Terlepas dari permasalahan tersebut ada empat motif karyawan dalam bekerja yaitu bekerja karena alasan ekonomi, bekerja karena passion,dan bekerja untuk memperoleh pengakuan diri, serta bekerja karena ibadah. Atas dasar empat motif karyawan dalam bekerja mendorong LAZIS Jateng untuk membuat strategi agar karyawan tetap bekerja dan bertahan di dalam perusahaan. Selain itu, Lazis Jateng juga melakukan perampingan struktur sumber daya manusia agar aktivitas perusahaan berjalan dengan efektif dan efisien. Lazis Jateng juga sangat jarang melakukan pemutusan hubungan kerja pada karyawan. Sebaliknya justru perusahaan komitmen untuk mengembangkan kompetensi dan karir pada karyawan yang memiliki semangat dan keinginan untuk terus bertahan dan berkembang bersama LAZIS Jateng.

Berikut ini adalah tabel informasi terkait karyawan yang resign di Lembaga Amil Zakat, Infaq dan Shadaqah Al Ihsan Jawa Tengah (LAZIS JATENG) pada tahun 2019.

Tabel 1. Data Karyawan Resign Januari-November 2019 Lazis Al Ihsan Jawa Tengah

\begin{tabular}{llll}
\hline No & Kantor & Posisi & Jumlah \\
\hline 1. & Kantor Pusat & Media & 2 \\
& & Program & 2 \\
& & Admin Program & 1 \\
& & Admin Fundraising & 1 \\
& & Keuangan & 1 \\
2. & Semarang & LKSA & 1 \\
& & Fundraising & 1 \\
3. & Kabupaten Semarang & Program & 1 \\
4. & Solo & Fundraising & 1
\end{tabular}




\begin{tabular}{lll}
$5 . \quad$ Wonogiri & Keuangan & 1 \\
\hline Total & $\mathbf{1 2}$ \\
\hline
\end{tabular}

Sumber: Data Lazis Jateng Al Ihsan

Pada kasus pegawai LAZ Al Ihsan Jateng intensitas untuk melakukan sesuatu, baik intention to stay maupun turnover intention jelas memberikan dampak yang berbeda. Perilaku intention to stay tentu akan menguntungkan bagi lembaga namun sebaliknya perilaku turnover intention akan merugikan lembaga. Oleh karena itu, kedua hal tersebut patut menjadi perhatian besar bagi manajemen. Manajemen harus jeli dalam memberikan penilaian manakala menginginkan keuntungan atau dampak positif dari perilaku tersebut. Perilaku intention to stay karyawan dapat dikendalikan oleh manajemen dengan memberikan dan memenuhi keinginan serta kebutuhan karyawan dalam bekerja. Sehingga karyawan akan mendapatkan rasa nyaman dan semangat dalam melaksanakan kerja yang sesuai dengan pekerjaannya.

Makna intention adalah niat atau keinginan yang timbul dari individu untuk melakukan sesuatu. Oleh karena itu, Intention to Stay (ITS) dapat didefinisikan sebagai kecenderungan atau niat karyawan untuk tetap bekerja dalam pekerjaannya secara sukarela menurut pilihannya sendiri. Adapun menurut Castle et al (2007) keinginan karyawan untuk tinggal di perusahaan dipengaruhi oleh karakteristik personal, karakteristik yang berhubungan dengan peran dalam perusahaan, karakteristik fasilitas perusahaan, peluang terjadinya perputaran karyawan dan karakteristik pekerjaan.

Salah satu perspektif pendekatan pada komitmen organisasional adalah sebagai suatu keadaan dimana seseorang karyawan memihak organisasi tertentu serta tujuan dan keinginannya untuk mempertahankan keanggotaan dalam organisasi tersebut. Menurut Robbins, didefinisikan bahwa keterlibatan pekerjaaan yang tinggi berarti memihak pada pekerjaan tertentu seseorang individu, sementara komitmen organisasional yang tinggi berarti memihak organisasi yang merekrut individu tersebut. Dalam organisasi seperti LAZIS Al Ihsan Jateng, karyawan merupakan tenaga profesional yang mampu menjalankan kebijakan-kebijakan dengan tujuan-tujuan tertentu dan mempunyai komitmen yang kuat terhadap organisasi tempat dia bekerja.

Konteks yang perlu diperhatikan dalam setiap individu atau karyawan agar memunculkan perilaku intention to stay pada karyawan terdiri dari daya fikir (rohani) dan daya fisik (jasmani). Dua hal tersebut tidak bisa dikesampingkan karena berhubungan dengan kesehatan karyawan, yakni sehat secara jasmani dan rohaninya. Sehat secara rohani berarti berkaitan dengan spiritualitas seseorang. Podsakoff dkk (2000) memberikan pengertian bahwa spiritualitas di tempat kerja merupakan fenomena yang bersifat universal, dimana organisasi mengaku bahwa orang yang bekerja dalam suatu organisasi perusahaan memiliki kehidupan batiniah tumbuh karena kebermaknaan pekerjaan bagi kehidupannya. Sebagai manusia maka orang memiliki pikiran dan roh serta selalu berusaha menemukan makna dan tujuan hidup dalam pekerjaan mereka. Beberapa hasil penelitian menunjukkan bahwa semakin tinggi spiritualitas karyawan mereka cenderung untuk memiliki perilaku di luar pekerjaan dalam menjalankan pekerjaan mereka sehari-hari sehingga mendukung efektivitas organisasi.

Ada beberapa faktor yang menyebabkan karyawan ingin keluar atau resign dari suatu organisasi atau perusahaan. Penyebab yang sering muncul yakni terkait pekerjaan yang kurang sesuai, kesempatan untuk mendapatkan pekerjaan yang lebih baik dan lingkungan kerja yang kurang mendukung. Suatu perusahaan membutuhkan penanganan yang tepat untuk meyakinkan para karyawan agar tidak resign dan tetap loyal. Bagi perusahaan yang sedang berkembang dan menata manajemen dengan baik maka mengelola karyawan agar tetap loyal adalah sebuah keuntungan karena perusahaan mampu mempertahankan karyawan terbaiknya. Sehingga perusahaan bisa fokus untuk meningkatkan kinerja karyawan. Hal 
sederhana yakni memberikan kenyamanan di tempat kerja bisa menjadi faktor penentu betah tidaknya karyawan di perusahaan. Kenyamanan tersebut bisa didapatkan oleh karyawan dengan cara mendapatkan kesesuaian individu dengan pekerjaannya.

Kesesuaian individu dengan pekerjaannya menimbulkan hal positif dan memiliki standar kemampuan dan keahlian seperti apa yang dibutuhkan untuk menyelesaikan tugasnya. Selalu merasa cocok dengan pekerjaannya, selalu memberikan hasil yang terbaik bagi organisasi dan konsumennya. Farzaneh (2014:674) menyatakan bahwa person job fit merupakan kebutuhan kesesuaian yang terjadi ketika pasokan yang ditawarkan oleh pekerjaan kompatibel dengan kebutuhan, preferensi dan keinginan individu. Pendapat tersebut diperkuat oleh Newton dkk (2009:6) yang menyatakan person job fit melibatkan kesesuaian orang dan persyaratan yang secara langsung terkait dengan pekerjaan tertentu. Kesesuaian individu dengan pekerjaan akan menguntungkan individu karena individu akan bekerja dengan segenap kemampuan yang dimiliki dan karyawan merasakan senang dan puas karena bekerja sesuai pada bidang yang ditekuni.

\section{Kajian Teori dan Telaah Literatur}

\section{Intention to Stay}

Intention to Stay dapat didefinisikan sebagai kecenderungan atau niat karyawan untuk tetap bekerja dalam pekerjaannya secara sukarela menurut pilihannya sendiri. Pengukuran variabel intention to stay dikembangkan dari Mowday et al dalam Siaahan (2014) yang indikatornya meliputi: (1) Karyawan tidak pernah berniat atau memikirkan untuk berhenti dari pekerjaannya saat ini. (2) Karyawan tidak pernah memikirkan untuk mencari secara aktif perusahaan lain untuk pindah bekerja di tahun-tahun berikutnya. (3) Bila karyawan memperoleh pekerjaan yang sama dengan kondisi pendapatan yang sama di perusahaan lain, karyawan tetap tidak akan meninggalkan perusahaan. (4) Karyawan merasa rugi jika berhenti dari pekerjaan saat ini.

\section{Organizational Commitment}

Allen and Meyer (1993) mengemukakan bahwa komitmen organisasional sebagai sebuah keadaan psikologi yang mengkarakteristikkan hubungan karyawan dengan organisasi atau implikasinya yang mempengaruhi apakah karyawan akan tetap bertahan dalam organisasi atau tidak, yang teridentifikasi dalam tiga komponen yaitu: (1) Komitmen afektif (affective commitment) (2) Komitmen kontinyu (continuance commitment) (3) Komitmen normatif (normative commitment).

\section{Workplace Spirituality}

Workplace Spirituality adalah mendeskripsikan spiritualitas di tempat kerja terkait dalam dua aspek yaitu pengalaman individu dan lingkungan organisasi. Spiritualitas di tempat kerja muncul karena individu dapat mengekspresikan diri secara pribadi dengan melakukan arti kerja dalam komunitas mereka (Ashmos dan Duchon, 2000). Menurut Ashmos dan Duchon (2000), terdapat beberapa indikator dalam workplace spirituality ini, antara lain: (1) Kondisi lingkungan atau kelompok (2) Kebermaknaan pada pekerjaan (3) Hakikat yang dirasakan dalam diri (4) Pemahaman spiritualitas yang jelas (5) Tanggung jawab secara pribadi (6) Menjalin hubungan yang baik dengan orang lain (7) Kontemplasi atau perenungan diri.

\section{Person Job Fit}

Person Job Fit adalah keadaan yang menggambarkan adanya kesesuaian antara kemampuan karyawan dengan tuntutan pekerjaan, kebutuhan individu dan apa yang dapat diberikan oleh 
pekerjaan itu kepada karyawan (Cable \& Derue, 2002). Menurut Daniel dan Elizabeth dalam Hanum (2014) terdapat dua indikator person-job fit, yaitu: (1) Supply-Value Fit (Nilai,Tujuan, Kebutuhan Psikologis, Minat, Gaji) (2) Demands-Abilities Fit (Keahlian, kemampuan, pengetahuan).

\section{Model Penelitian}

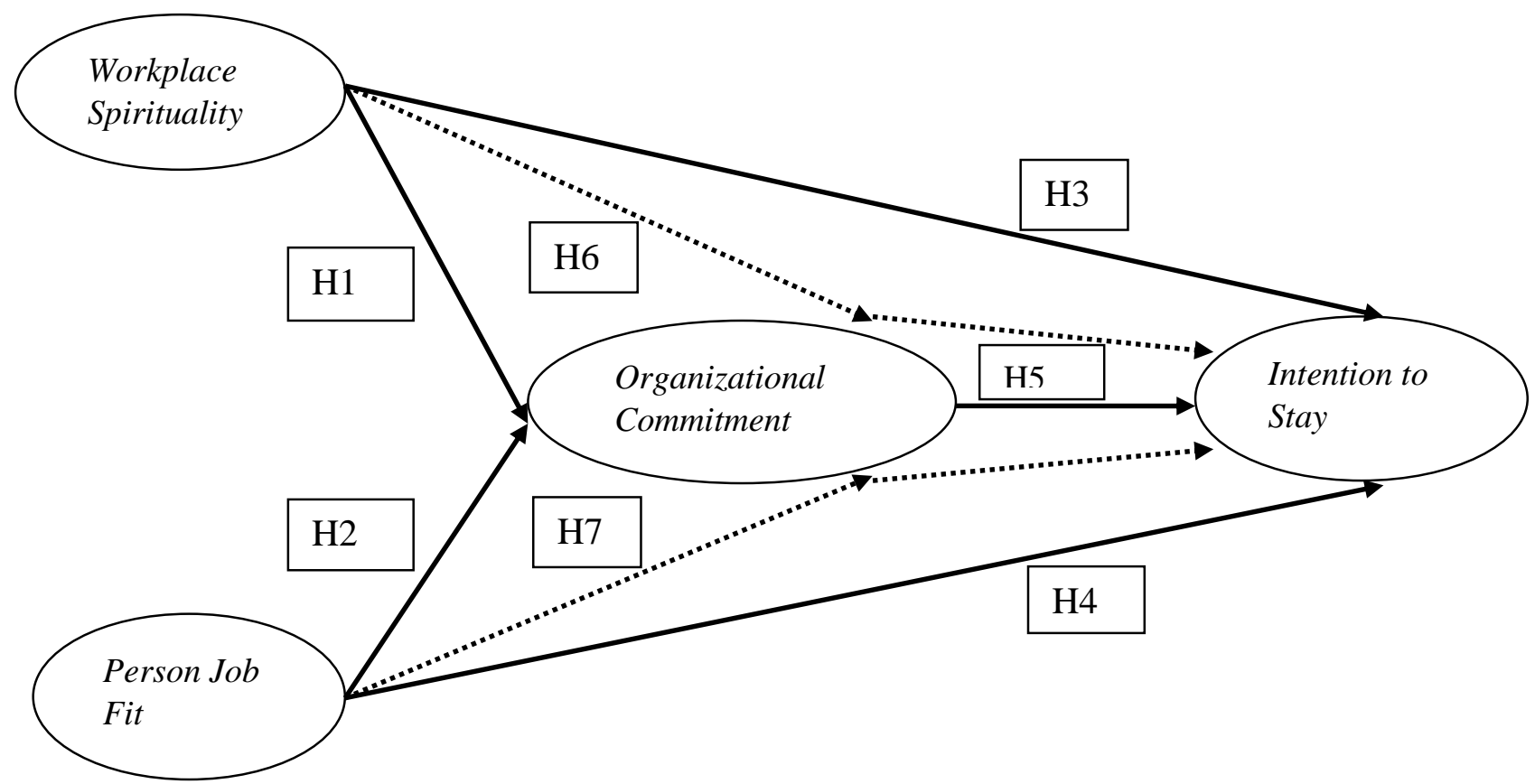

Gambar 1. Model penelitian

\section{Metode Penelitian}

Penelitian ini dilakukan pada pegawai Lazis Al Ihsan Jawa Tengah. Pengambilan sampel menggunakan metode non probability sampling. Dalam penelitian ini, pengambilan sampel menggunakan seluruh populasi yang berjumlah 53 pegawai, sehingga sampel yang digunakan adalah sampel jenuh. Pengumpulan data menggunakan kuesioner dengan skala likert, dengan masing-masing kuesioner mengenai intention to stay 8 item pertanyaan, kuesioner organizational commitment 6 item pertanyaan, kuesioner workplace spirituality 7 item pertanyaan dan kuesioner person job fit 4 item pertanyaan.

Teknik pengumpulan data yang dilakukan dengan cara : (1) observasi (2) wawancara (3) menyebar kuesioner; (4) studi pustaka. Instrumen dalam penelitian ini dilakukan dengan menggunakan kuesioner yang ditujukan untuk memperoleh jawaban responden. Alat bantu pengolahan data menggunakan SPSS for windows versi 24 . Teknik analisis data yang digunakan meliputi: (1) Uji Validitas dan Uji Reliabilitas (2) Uji Asumsi Klasik (3) Uji Hipotesis (4) Analisis Korelasi (5) Analisis Jalur (6) Uji Sobel. 


\section{Hasil dan Pembahasan}

\section{Uji Validitas}

Tabel 2. Hasil Uji Validitas Variabel Organizational Commitment (Y1)

\begin{tabular}{ccccc}
\hline Variabel & Butir & R hitung & $\begin{array}{c}\mathbf{R} \\
\text { tabel }\end{array}$ & Keterangan \\
\hline & 1 & 0,512 & 0,2706 & Valid \\
Organizational & 2 & 0,837 & 0,2706 & Valid \\
Commitment & 3 & 0,793 & 0,2706 & Valid \\
& 4 & 0,780 & 0,2706 & Valid \\
& 5 & 0,651 & 0,2706 & Valid \\
& 6 & 0,766 & 0,2706 & Valid \\
\hline
\end{tabular}

Sumber: Data primer diolah, 2019

Tabel 3. Hasil Uji Validitas Varibel Intention to Stay (Y2)

\begin{tabular}{ccrcc}
\hline Variabel & Butir & R hitung & R tabel & Keterangan \\
\hline & 1 & 0,803 & 0,2706 & Valid \\
& 2 & 0,758 & 0,2706 & Valid \\
Intention to & 3 & 0,757 & 0,2706 & Valid \\
Stay & 4 & 0,622 & 0,2706 & Valid \\
& 5 & 0,875 & 0,2706 & Valid \\
& 6 & 0,768 & 0,2706 & Valid \\
& 7 & 0,741 & 0,2706 & Valid \\
& 8 & 0,728 & 0,2706 & Valid \\
\hline
\end{tabular}

Sumber: Data primer diolah, 2019

Tabel 4. Hasil Uji Validitas Variabel Workplace Spirituality (X1)

\begin{tabular}{ccccc}
\hline Variabel & Butir & R hitung & R tabel & Keterangan \\
\hline & 1 & 0,660 & 0,2706 & Valid \\
& 2 & 0,726 & 0,2706 & Valid \\
Workplace & 3 & 0,817 & 0,2706 & Valid \\
Spirituality & 4 & 0,803 & 0,2706 & Valid \\
& 5 & 0,804 & 0,2706 & Valid \\
& 6 & 0,830 & 0,2706 & Valid \\
& 7 & 0,800 & 0,2706 & Valid \\
\hline
\end{tabular}

Sumber: Data primer diolah, 2019

Tabel 5. Hasil Uji Validitas Variabel Person Job Fit (X2)

\begin{tabular}{ccccc}
\hline Variabel & Butir & R hitung & R tabel & Keterangan \\
\hline Person Job & 1 & 0,859 & 0,2706 & Valid \\
Fit & 2 & 0,852 & 0,2706 & Valid \\
& 3 & 0,762 & 0,2706 & Valid \\
& 4 & 0,873 & 0,2706 & Valid \\
\hline
\end{tabular}

Sumber: Data primer yang diolah, 2019

Berdasarkan tabel di atas menunjukkan semua instrumen intention to stay, organizational commitment, workplace spirituality, dan person job fit dinyatakan valid karena $r$ hitung $>$ rtabel $(0,2706)$, dengan tingkat signifikansi sebesar 0,000 < 0,05 sehingga semua item yang dipakai dinyatakan valid atau sah. 


\section{Uji Reliabilitas}

Tabel 6. Hasil Uji Reliabilitas

\begin{tabular}{clccl}
\hline No. & \multicolumn{1}{c}{ Variabel } & R alpha & $\begin{array}{c}\text { Batas } \\
\text { Penerimaan }\end{array}$ & Keterangan \\
\hline 1 & Workplace Spirituality & 0,889 & 0,60 & Reliabel \\
2 & Person Job Fit & 0,855 & 0,60 & Reliabel \\
3 & Organizational & 0,823 & 0,60 & Reliabel \\
& Commitment & & & \\
4 & Intention to Stay & 0,891 & 0,60 & Reliabel \\
\hline Sumber: Data primer diolah, 2019 & & &
\end{tabular}

Berdasarkan Tabel tersebut hasil analisis dapat dijelaskan bahwa instrumen-instrumen yang digunakan dalam penelitian ini memiliki nilai Cronbach's Alpha $>\mathrm{r}_{\text {kritis }}(0,60)$. Berdasarkan hasil tersebut, dapat disimpulkan bahwa semua instrumen dalam penelitian dinyatakan reliabel.

\section{Uji Normalitas}

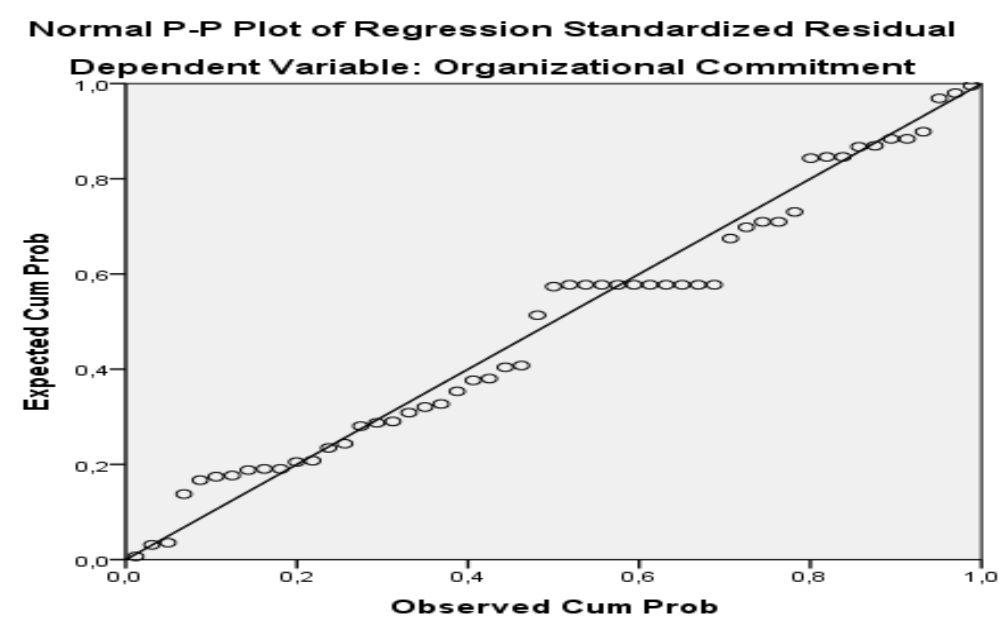

Gambar 2. Hasil uji normalitas substruktural 1 Sumber: Data primer diolah, 2020

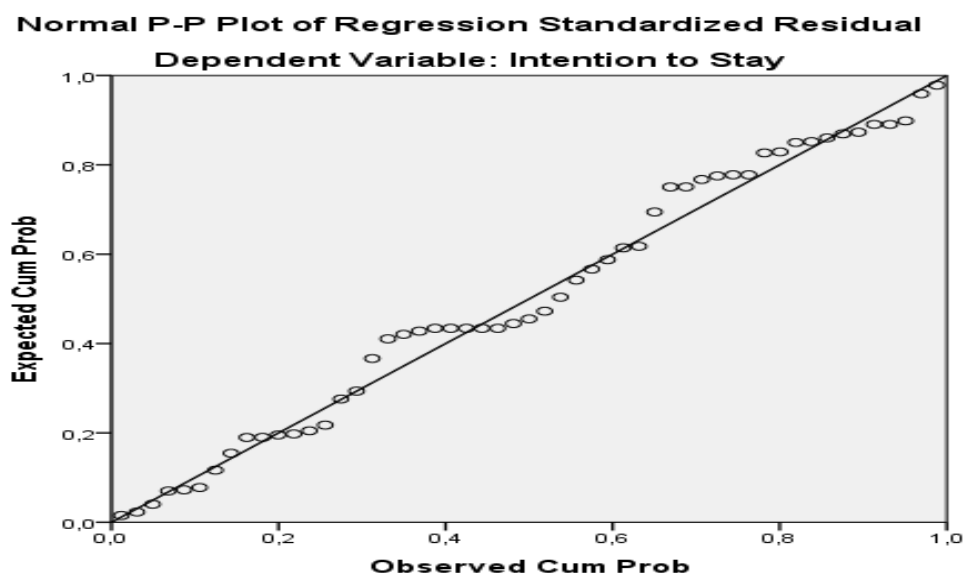

Gambar 3. Hasil uji normalitas substruktural 2

Sumber: Data primer diolah, 2020 
Berdasarkan gambar tersebut (Normal P-P Plot of Regression Standardized Residual) diketahui bahwa data menyebar disekitar garis diagonal. Maka model regresi tersebut memenuhi asumsi normalitas.

\section{Uji Multikolinearitas}

Tabel 7. Hasil Uji Multikolinieritas Sub Struktural I

\begin{tabular}{cccc}
\hline \multirow{2}{*}{ No } & \multirow{2}{*}{ Model } & \multicolumn{2}{c}{ Collinieritas Statistics } \\
\cline { 2 - 4 } & Wolerance & VIF \\
\hline 1 & Workplace Spirituality & 0,529 & 1,890 \\
2 & Person Job Fit & 0,529 & 1,890 \\
\hline \multicolumn{2}{c}{ Sumber: Data primer } & diolah, 2019
\end{tabular}

Tabel 8. Hasil Uji Multikolinieritas Sub Struktural II

\begin{tabular}{clcc}
\hline \multirow{2}{*}{ No. } & \multicolumn{1}{|c}{ Model } & \multicolumn{2}{c}{ Collinieritas Statistics } \\
\cline { 3 - 4 } & & Tolerance & VIF \\
\hline 1 & Workplace Spirituality & 0,520 & 1,924 \\
2 & Person Job Fit & 0,410 & 2,442 \\
3 & Organizational & 0,563 & 1,775 \\
& Commitment & & \\
\hline
\end{tabular}

Sumber: Data primer yang diolah, 2019

Berdasarkan Tabel di atas coeficient di atas dapat dijelaskan bahwa pada bagian collinieritas statistic menunjukan angka VIF tidak lebih besar dari 10 dan tolerance lebih dari 0,10. Berdasarkan hasil tersebut dapat diketahui bahwa model regresi substruktural II ini tidak terdapat multikolonieritas, sehingga model ini dapat dipakai.

\section{Uji Heteroskedastisitas}

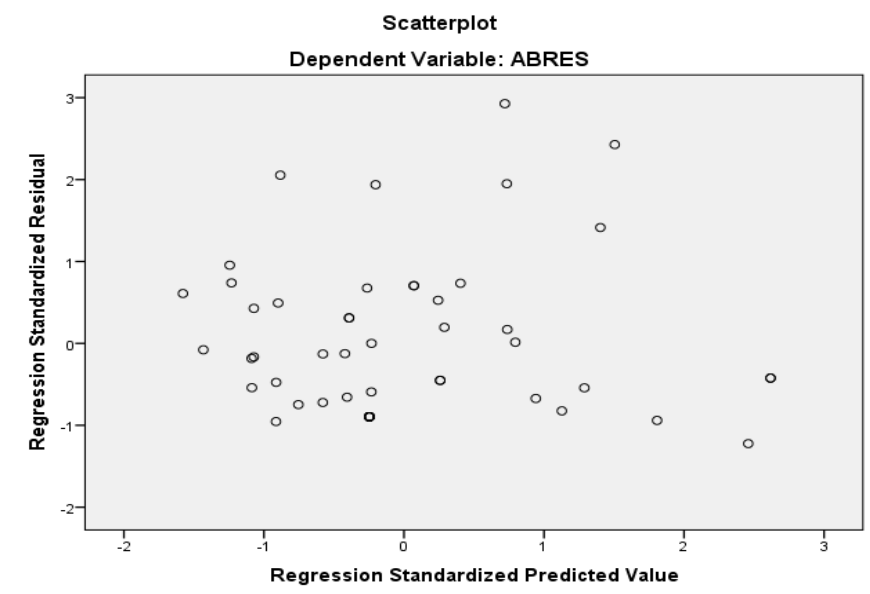

Gambar 4. Hasil Uji Heteroskedastisitas Sub Struktural I Sumber: Data primer yang diolah, 2019 


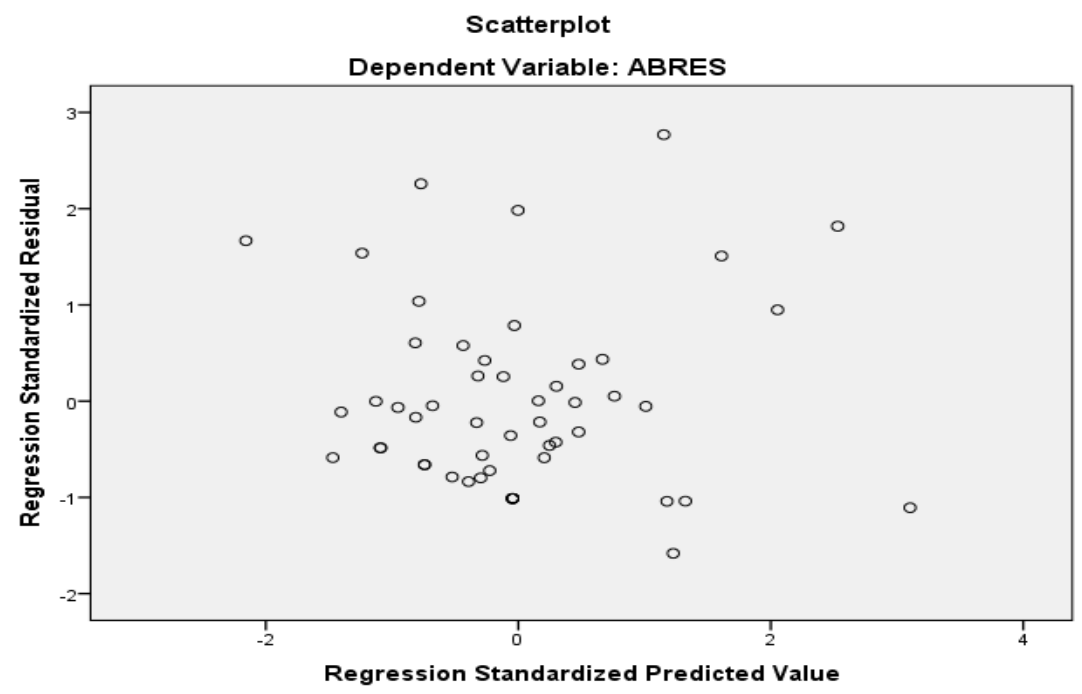

Gambar 5. Hasil Uji Heteroskedastisitas Sub Struktural II Sumber: Data primer yang diolah, 2019

Berdasarkan gambar grafik heteroskedastisitas di atas menunjukan bahwa tidak ada pola tertentu, seperti titik-titik (poin) yang membentuk suatu pola tertentu yang teratur (bergelombang, melebar, kemudian menyempit) dan tidak ada pola yang jelas, maka dapat disimpulkan model regresi dalam penelitian ini tidak terjadi heteroskedastisitas.

\section{Uji Hipotesis}

\section{Uji-t}

Tabel 9. Hasil Uji t Substruktural I

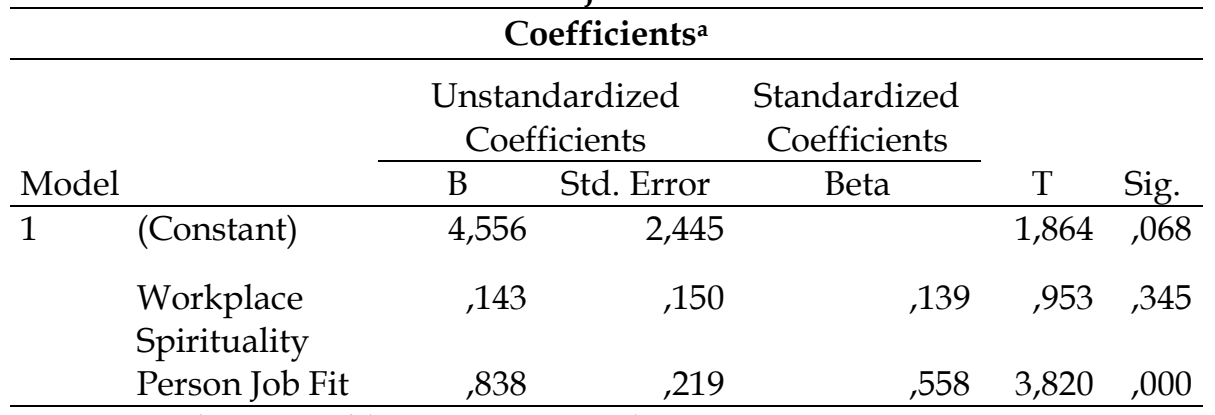

a. Dependent Variable: Organizational Commitment Sumber: Data primer yang diolah, 2019

Berdasarkan tabel diatas dapat dianalisa bahwa :

Nilai $\mathrm{t}_{\text {hitung }}$ workplace spirituality sebesar $0,953<2,007$ dan signifikansi sebesar $0,345>0,05$ sehingga $\mathrm{H} 0$ diterima sedangkan $\mathrm{H} 1$ ditolak. Artinya, workplace spirituality tidak berpengaruh secara signifikan terhadap organizational commitment. Faktor besarnya pengaruh workplace spirituality terhadap organizational commitment sebesar 0,139 atau 13,9\%.

Nilai $t_{\text {hitung }}$ person job fit sebesar 3,820>2,007 dan signifikansi sebesar 0,000<0,05 sehingga H0 ditolak sedangkan $\mathrm{H} 2$ diterima. Artinya, person job fit berpengaruh secara signifikan terhadap organizational commitment. Faktor besarnya pengaruh person job fit terhadap organizational commitment sebesar 0,558 atau $55,8 \%$. 
Tabel 10. Hasil Uji t Substruktural II

\begin{tabular}{|c|c|c|c|c|c|c|}
\hline & & Coe & ficients & & & \\
\hline & & $\begin{array}{r}\text { Unstand } \\
\text { Coeffi }\end{array}$ & $\begin{array}{l}\text { rdized } \\
\text { ents }\end{array}$ & $\begin{array}{c}\text { Standardized } \\
\text { Coefficients }\end{array}$ & & \\
\hline Model & & $\mathrm{B}$ & $\begin{array}{l}\text { Std. } \\
\text { Error }\end{array}$ & Beta & $\mathrm{t}$ & Sig. \\
\hline 1 & (Constant) & 4,167 & 2,716 & & 1,534 & ,131 \\
\hline & Workplace &,- 509 & ,162 &,- 326 & $-3,140$ & ,003 \\
\hline & Spirituality & & & & & \\
\hline & Person Job Fit & 678 & 268 & 296 & 2,530 & ,015 \\
\hline & $\begin{array}{l}\text { Organizational } \\
\text { Commitment }\end{array}$ & 1,208 & 152 & ,792 & 7,952 & ,000 \\
\hline
\end{tabular}

a. Dependent Variable: Intention to Stay

Sumber: Data primer yang diolah, 2019

Berdasarkan Tabel diatas dapat dianalisa bahwa:

Nilai $t_{\text {hitung }}$ workplace spirituality sebesar $-3,140>2,008$ dan signifikansi sebesar $0,003<0,05$ sehingga $\mathrm{H} 0$ ditolak sedangkan $\mathrm{H} 3$ diterima. Artinya, workplace spirituality berpengaruh negatif secara signifikan terhadap intention to stay. Faktor besarnya pengaruh workplace spirituality terhadap intention to stay sebesar $-0,326$ atau 32,6\%.

Nilai $\mathbf{t}_{\text {hitung }}$ person job fit sebesar 2,530>2,008 dan signifikansi sebesar 0,015<0,05 sehingga H0 ditolak sedangkan $\mathrm{H} 4$ diterima. Artinya, person job fit berpengaruh secara signifikan terhadap intention to stay. Faktor besarnya pengaruh person job fit terhadap intention to stay sebesar 0,296 atau $29,6 \%$.

Nilai thitung organizational commitment sebesar 7,952>2,008 dan signifikansi sebesar 0,000<0,05 sehingga H0 ditolak sedangkan $\mathrm{H} 5$ diterima. Artinya, organizational commitment berpengaruh secara signifikan terhadap intention to stay. Faktor besarnya pengaruh organizational commitment terhadap intention to stay sebesar 0,792 atau 79,2\%.

\section{Koefisien Determinasi $\left(\mathbf{R}^{2}\right)$}

Tabel 11. Hasil Uji Koefisien Determinasi Substruktural I

\begin{tabular}{lcccc}
\hline \multicolumn{4}{c}{ Model Summary } \\
\hline Model & $\mathrm{R}$ & R Square & $\begin{array}{c}\text { Adjusted R } \\
\text { Square }\end{array}$ & $\begin{array}{c}\text { Std. Error of the } \\
\text { Estimate }\end{array}$ \\
\hline 1 &, $661^{\mathrm{a}}$ &, 437 &, 414 & 2,00101 \\
\hline a. Predictors: (Constant), Workplace Spirituality, Person Job Fit \\
b. Dependent Variable: Organizational Commitment \\
Sumber: Data primer yang diolah, 2019
\end{tabular}

Berdasarkan Tabel diatas besarnya Adjusted R Square adalah 0,414 hal ini berarti 41,4\% organizational commitment dapat dijelaskan oleh workplace spirituality dan person job fit. Sedangkan sisanya $(100 \%-41,4 \%)=58,6 \%$ dijelaskan oleh faktor lain diluar model. 
Tabel 12. Hasil Uji Koefisien Determinasi Substruktural II

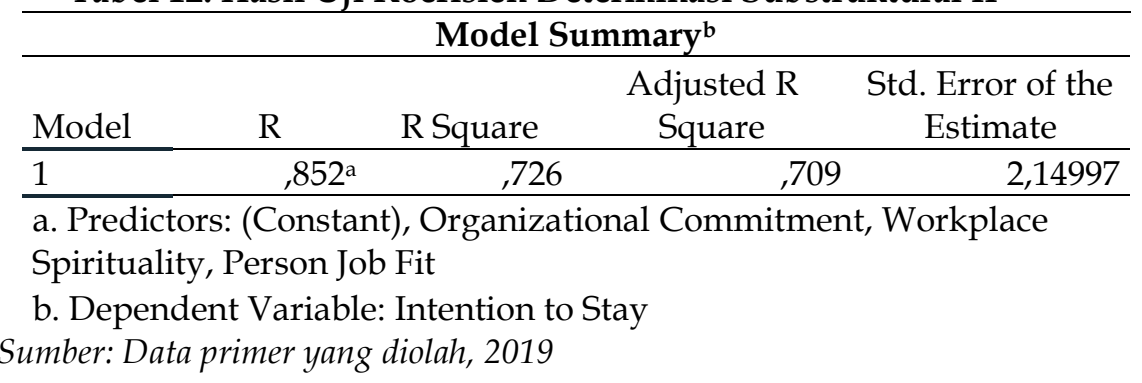

Berdasarkan Tabel diatas besarnya Adjusted R Square adalah 0,709 hal ini berati 70,9\% intention to stay dapat dijelaskan oleh workplace spirituality, person job fit, dan organizational commitment. Sedangkan sisanya $(100 \%-70,9 \%)=29,1 \%$ dijelaskan oleh faktor lain diluar model.

\section{Analisis Korelasi}

Tabel 13. Hasil Uji Korelasi

\begin{tabular}{llrr}
\hline \multicolumn{1}{c}{ Correlations } \\
\hline & \multicolumn{1}{c}{$\begin{array}{c}\text { Workplace } \\
\text { Spirituality }\end{array}$} & Person Job Fit \\
\hline Workplace & Pearson Correlation & 1 &, $686^{* *}$ \\
Spirituality & Sig. (2-tailed) & 53 &, 000 \\
& N & 53 \\
Person Job Fit & Pearson Correlation &, $686^{* *}$ & 1 \\
& Sig. (2-tailed) &, 000 & \\
& N & 53 & 53 \\
\hline
\end{tabular}

**. Correlation is significant at the 0.01 level (2-tailed).

Sumber: Data primer yang diolah, 2019

Berdasarkan tabel diatas dapat dijelaskan bahwa workplace spirituality memiliki hubungan dengan person job fit sebesar 0,686 dan masuk kategori ke tingkatan hubungan korelasi kuat. 


\section{Analisis Jalur}

\section{Koefisien Jalur}

Tabel 14. Hasil Uji Analisis Jalur Substruktural I

\begin{tabular}{|c|c|c|c|c|c|c|c|}
\hline \multicolumn{8}{|c|}{ Model Summary } \\
\hline Model & $\mathrm{R}$ & R Square & $\begin{array}{l}\text { Adjusted R } \\
\text { Square }\end{array}$ & \multicolumn{4}{|c|}{$\begin{array}{l}\text { Std. Error of } \\
\text { the Estimate }\end{array}$} \\
\hline 1 & ,661 a & , 437 & ,414 & \multicolumn{2}{|c|}{2,00101} & & \\
\hline \multicolumn{8}{|c|}{ a. Predictors: (Constant), Person Job Fit, Workplace Spirituality } \\
\hline \multicolumn{8}{|c|}{ Coefficients $^{a}$} \\
\hline \multicolumn{8}{|c|}{$\begin{array}{l}\text { Unstandardized } \\
\text { Coefficients }\end{array}$} \\
\hline \multicolumn{3}{|c|}{ Model } & $\mathrm{B}$ & Std. Error & Beta & $\mathrm{t}$ & Sig. \\
\hline \multirow[t]{3}{*}{1} & \multicolumn{2}{|l|}{ (Constant) } & 4,556 & 2,445 & \multirow[b]{2}{*}{,139 } & 1,864 & ,068 \\
\hline & \multicolumn{2}{|c|}{$\begin{array}{l}\text { Workplace } \\
\text { Spirituality }\end{array}$} & 143 & 150 & & ,953 & 345 \\
\hline & \multicolumn{2}{|c|}{ Person Job Fit } & ,838 & ,219 &, 558 & 3,820 &, 000 \\
\hline
\end{tabular}

a. Dependent Variable: Organizational Commitment

Sumber: Data primer diolah, tahun 2019

Tabel 15. Hasil Uji Analisis Jalur Substruktural II

Model Summary

\begin{tabular}{lr|r|r|r}
\hline Model & R & R Square & $\begin{array}{c}\text { Adjusted R } \\
\text { Square }\end{array}$ & $\begin{array}{l}\text { Std. Error of } \\
\text { the Estimate }\end{array}$ \\
\hline 1 &, $852^{\mathrm{a}}$ &, 726 &, 709 & 2,14997 \\
\hline
\end{tabular}

a. Predictors: (Constant), Organizational Commitment,

Workplace Spirituality, Person Job Fit

Coefficientsa

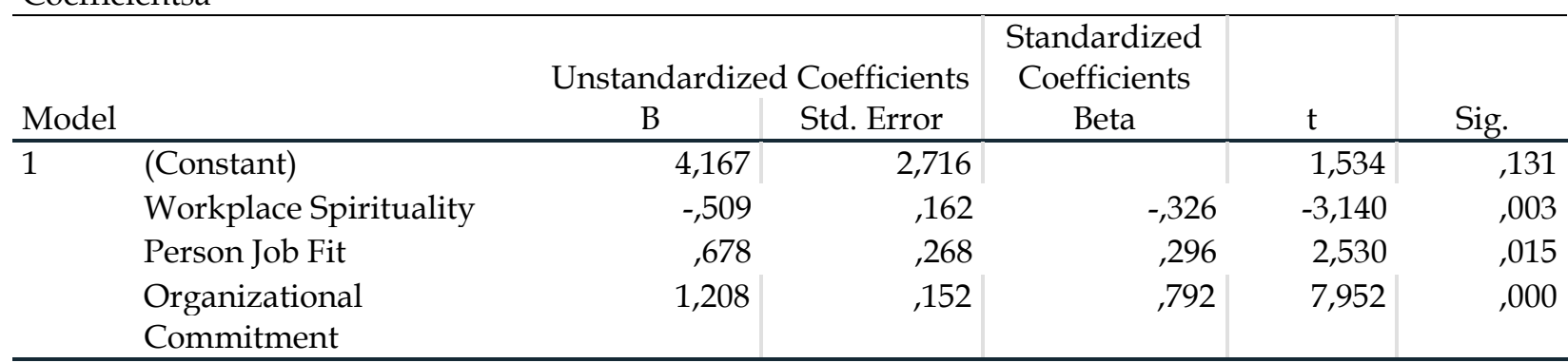

a. Dependent Variable: Intention to Stay

Sumber: Data primer yang diolah, 2019 


\section{Diagram Jalur}

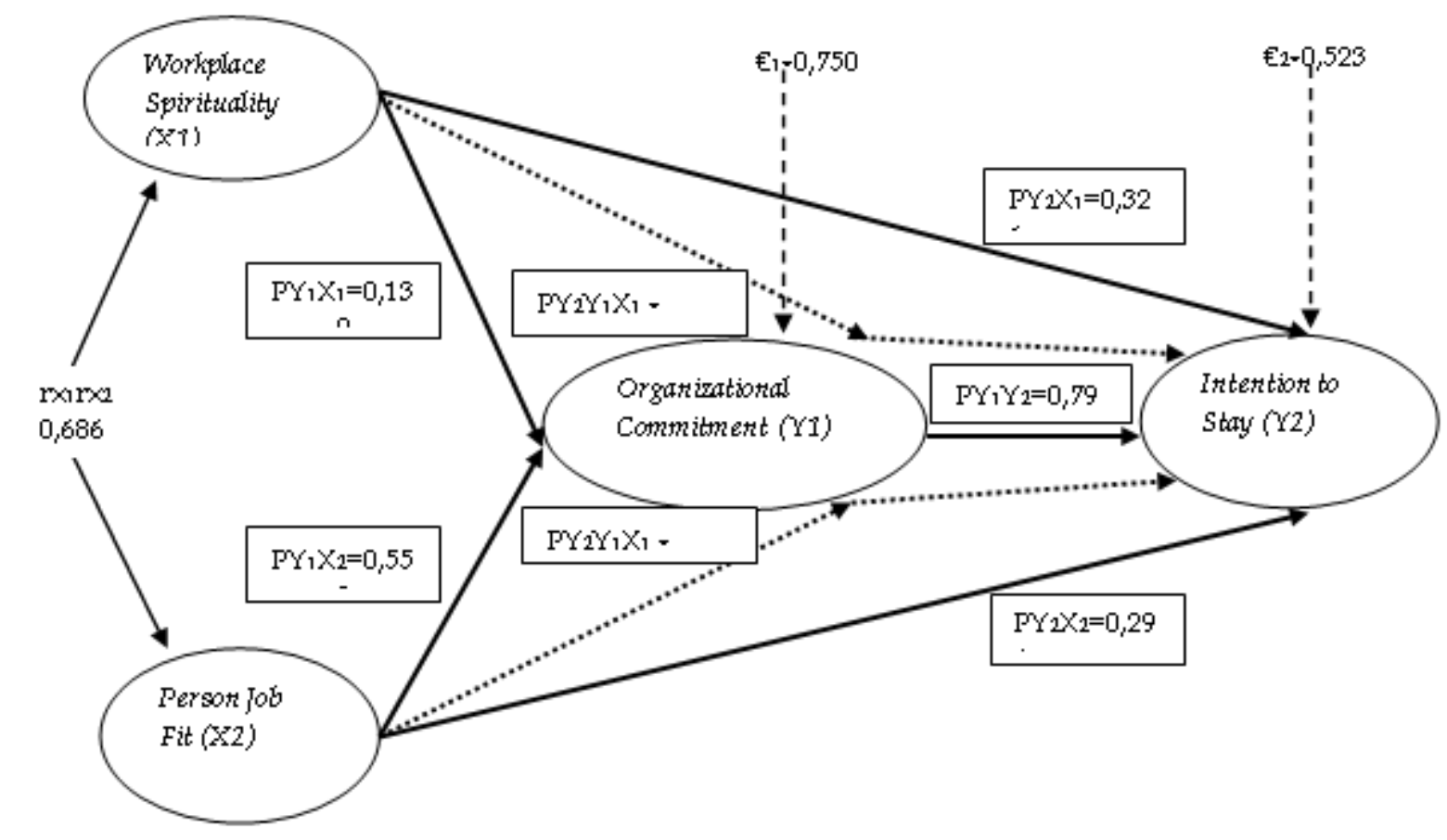

Gambar 6. Diagram Jalur

\section{Uji Sobel}

\begin{tabular}{|c|c|c|c|c|}
\hline Input: & & Test statistic: & Std. Error: & p-value: \\
\hline a 0.143 & Sobel test: & -0.91690076 & 0.07938373 & 0.35919465 \\
\hline \begin{tabular}{l|l} 
b & -0.509
\end{tabular} & Aroian test: & -0.88127242 & 0,08259308 & 0.37817039 \\
\hline$S_{a} 0.150$ & Goodman test: & -0.95723192 & 0.07603904 & 0.33845021 \\
\hline sb 0.152 & Reset all & \multicolumn{3}{|c|}{ Calculate } \\
\hline
\end{tabular}

\section{Gambar 7. Hasil Uji Sobel Substruktural I}

Berdasarkan hasil perhitungan sobel test diperoleh nilai test statistic -0.92 dan $p$-value $>0,05$. Hal tersebut berarti dapat disimpulkan bahwa organizational commitment tidak memediasi hubungan workplace spirituality dengan intention to stay. 


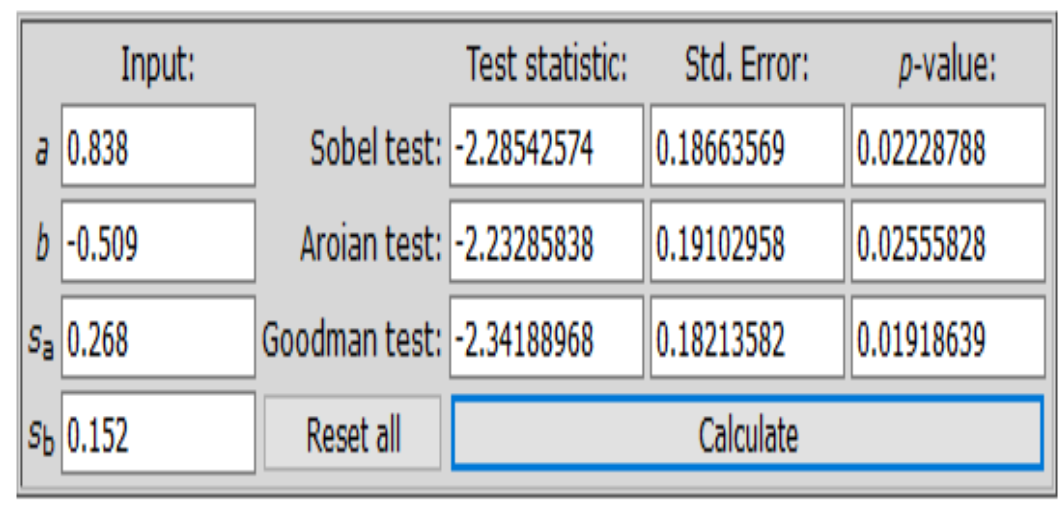

Gambar 8. Hasil Uji Sobel Súbstruktural II

Berdasarkan hasil perhitungan sobel test diperoleh nilai test statistic $-2,28$ dan $p$-value $<0,05$. Hal tersebut berarti dapat disimpulkan bahwa organizational commitment memediasi hubungan person job fit dengan intention to stay.

\section{Pembahasan}

Penelitian ini bertujuan untuk mengetahui seberapa besar pengaruh variabel independen (bebas) yaitu workplace spirituality dan person job fit terhadap variabel terikat (dependen) yaitu intention to stay dengan organizational commitment sebagai variabel intervening. Pembahasan lebih lanjut dari hasil penelitian ini adalah sebagai berikut:

\section{Pengaruh workplace spirituality terhadap organizational commitment}

Hasil penelitian menunjukan workplace spirituality tidak berpengaruh secara signifikan terhadap organizational commitment. Hal ini menunjukan bahwa workplace spirituality dapat dipertimbangkan perusahaan dalam membangun organizational commitment di LAZIS Al Ihsan Jateng. Artinya, workplace spirituality memiliki pengaruh terhadap organizational commitment karyawan walau hanya sedikit. Perusahaan dapat mempertimbangkan indikator workplace spirituality mana yang harus dikembangkan untuk meningkatkan komitmen karyawan. Indikator yang bisa dikuatkan di dalam Lazis Jateng yaitu kondisi lingkungan atau kelompok, kebermaknaan pada pekerjaan, dan pemahaman spiritualitas yang jelas.

\section{Pengaruh person job fit terhadap organizational commitment}

Hasil penelitian menunjukan bahwa person job fit berpengaruh secara signifikan terhadap organizational commitment. Hal ini menunjukan bahwa person job fit mempengaruhi organizational commitment. Artinya, semakin tinggi person job fit karyawan maka semakin tinggi pula organizational commitment karyawan. Ketika Lazis Jateng menjamin karyawan terdapat kesesuaian antara pekerjaan dengan kualifikasi yang dimilikinya maka akan membuat karyawan senang dan menyatakan komitmen dengan perusahaan. Penelitian ini sejalan dengan penelitian terdahulu yang dilakukan oleh Leng, Chin (2016).

\section{Pengaruh workplace spirituality terhadap intention to stay}

Hasil penelitian menunjukan bahwa workplace spirituality berpengaruh negatif secara signifikan terhadap intention to stay. Hal ini menunjukan bahwa workplace spirituality bisa dijadikan acuan untuk mendorong keinginan karyawan untuk bertahan di dalam LAZIS Al Ihsan Jateng. Artinya, ketika LAZIS Jateng menjamin keadaan spiritualitas di tempat kerja maka karyawan akan memberikan imbal balik berupa menyatakan keinginannya untuk bertahan di dalam 
organisasi yang lebih tinggi. Sebaliknya, manakala LAZIS Jateng tidak menjamin keadaan spiritualitas di tempat kerja maka akan berpengaruh negatif terhadap rendahnya keinginan karyawan untuk bertahan di dalam organisasi. Contohnya, ketika karyawan tidak mendapatkan jaminan kondisi lingkungan atau kelompok seperti tidak mendapat pengakuan menjadi salah satu bagian dari komunitas atau keluarga di tempat kerja maka hal itu dapat mengurangi keinginannya untuk bertahan di dalam organisasi. Penelitian ini sejalan dengan penelitian terdahulu yang dilakukan oleh Milliman, Gatling, Kim (2018) dan Solichin (2019).

\section{Pengaruh person job fit terhadap intention to stay}

Hasil penelitian menunjukan bahwa person job fit berpengaruh secara signifikan terhadap intention to stay. Hal ini menunjukan bahwa semakin baik person job fit akan meningkatkan intention to stay karyawan. Penelitian ini sejalan dengan penelitian terdahulu yang dilakukan oleh Solichin (2019) dan Leng, Chin (2016).

\section{Pengaruh organizational commitment terhadap intention to stay}

Hasil penelitian menunjukan bahwa organizational commitment berpengaruh secara signifikan terhadap intention to stay. Hal ini menunjukan bahwa organizational commitment memiliki relevansi yang signifikan pada intention to stay. Semakin tinggi karyawan menyatakan komitmennya terhadap organisasi maka semakin tinggi pula keinginan karyawan untuk bertahan di LAZIS Al Ihsan Jateng. Penelitian ini tidak sejalan dengan penelitian terdahulu yang dilakukan oleh Steers dan Mowday (1981).

\section{Pengaruh workplace spirituality terhadap intention to stay melalui organizational commitment}

Berdasarkan analisis jalur dan uji sobel terdapat perbedaan hasil penelitian. Analisis jalur menunjukkan bahwa variabel organizational commitment memediasi variabel workplace spirituality terhadap intention to stay berdasarkan hasil analisis jalur dengan ketentuan pengaruh total lebih besar dari pengaruh langsung sebesar 0,931>0,326. Namun, berdasarkan hasil perhitungan sobel test diperoleh nilai test statistic -0.92 dan $p$-value $>0,05$. Artinya, variabel organizational commitment tidak memediasi variabel workplace spirituality terhadap intention to stay. Penelitian ini sejalan dengan penelitian terdahulu yang dilakukan oleh Rego, Cunha (2008).

\section{Pengaruh person job fit terhadap intention to stay melalui organizational commitment}

Berdasarkan analisis jalur dan uji sobel terdapat persamaan hasil penelitian. Hasil penelitian analisis jalur menunjukkan bahwa variabel organizational commitment memediasi variabel person job fit terhadap intention to stay dengan ketentuan pengaruh total lebih besar dari pengaruh langsung sebesar 1,35>0,296. Hal yang sama juga ditunjukkan berdasarkan hasil perhitungan sobel test diperoleh nilai test statistic -2,28 dan $p$-value $<0,05$ yang berarti dapat disimpulkan bahwa organizational commitment memediasi hubungan person job fit dengan intention to stay. Penelitian ini sejalan kaitannya dengan penelitian terdahulu yang dilakukan oleh Leng, Chin (2016).

\section{Simpulan}

Hasil penelitian ini memberikan implikasi pada kebijakan yang dilakukan oleh LAZIS Al Ihsan Jawa Tengah dalam meningkatkan komitmen dan niat untuk tinggal pegawai di dalam instansi atau lembaga tersebut yaitu:

Variabel workplace spirituality pada penelitian ini tidak menunjukkan adanya pengaruh terhadap organizational commitment. Artinya, faktor keadaan spiritualitas di tempat kerja 
(workplace spirituality) di LAZIS Al Ihsan Jawa Tengah tidak memiliki peran yang begitu penting dalam membantu pegawai untuk menyatakan komitmen di LAZIS Al Ihsan Jawa Tengah. Oleh karena itu, perusahaan diharapkan untuk memperhatikan variabel lain yang dapat meningkatkan keputusan pegawai dalam menyatakan komitmennya di dalam organisasi.

Pihak LAZIS Al Ihsan Jawa Tengah diharapkan untuk memperhatikan variabel person job fit (Kesesuaian individu dengan pekerjaannya) karena dalam penelitian ini menunjukkan bahwa variabel person job fit memiliki pengaruh yang signifikan terhadap keputusan pegawai dalam menyatakan komitmen dan niat untuk tinggal di LAZIS Al Ihsan Jawa Tengah.

Penelitian ini menunjukkan bahwa peran variabel commitment organizational sangat penting dalam membangun pengaruh yang positif antara workplace spirituality dan person job fit terhadap intention to stay. Oleh karena itu, LAZIS Al Ihsan Jawa Tengah harus memperhatikan faktor komitmen karyawan. Apabila komitmen karyawan tinggi maka akan berpengaruh terhadap faktor niat untuk tinggal di perusahaan. Hal itu bisa dilakukan dengan memberikan kesesuaian individu dengan pekerjaannya. Menurut Armstrong (1991), ada 10 komponen sebagai sebuah strategi bagi manajemen untuk meningkatkan komitmen anggota terhadap organisasi dalam mencapai tujuannya, yaitu: (a) Definisikan dan diseminasikan misi dan nilainilai organisasi; (b) Sebarkan tujuan organisasi dengan cara meningkatkan pemahaman tiap orang akan strategi organisasi dan ajak anggota organisasi untuk berpartisipasi dalam menterjemahkan tujuan ke dalam strategi; (c) Mengajak anggota organisasi untuk terlibat dalam mendefinisikan persoalan dan ikut terlibat dalam pemecahan sampai mereka merasa langkah itu adalah merupakan "milik"nya; (d) Berikan pola kepemimpinan transformasional yaitu memberikan anggota organisasi inspirasi ide yang mengarah pada masa depan; (e) Gunakan setiap media komunikasi yang ada untuk menyampaikan pesan secara tepat tentang misi, nilai, dan stratgei organisasi; (f) Berikan contoh-contoh dan pelatihan yang merupakan perwujudan dari gaya manajemen organisasi dalam meningkatkan keterlibatan dan kerjasama anggota; (g) Kembangkan proses dan iklim organisasi yang mampu meningkatkan perkembangan ketrampilan orang dalam mencapai tujuan prestasi yang lebih tinggi; (h) Kenalkan kepada anggota organisasi keuntungan (profit) organisasi dan rencana pencapaian profit untuk tahun-tahuan mendatang; (i) Gunakan program pelatihan yang ada untuk meningkatkan impresi yang bagus dari karyawan terutama karyawan baru terhadap organisasi; (j) Gunakan workshop atau jenis pelatihan lainnya untuk mengajak semua orang mendiskusikan isu-isu penting yang dihadapi organisasi dan berikan kesempatan pada mereka untuk memberikan kontribusi ide. Bahkan kalau perlu ambil tindakan mengenai ide-ide bagus mereka.

\section{Referensi}

Aboobaker, N., Edward, M., \& Zakkariya, K. A. (2019). Workplace spirituality, employee wellbeing and intention to stay. International Journal of Educational Management, 33, 28-44.

Adams, V.H., Snyder, C.R., Rand, K.L., Kings, E.A., Simpson, D.R., \& Pulvers, K.M. (2003). "Hope in workplace", in Giacalone, R.A. and Jurkiewicz, C.L. (Eds), The Handbook of Workplace Spirituality and Organizational Performance, M.E. Sharpe, Armonk, NY.

Allen, N. J., \& Meyer, J. P. (1990). The measurement and antecedents of affective, continuance and normative commitment to the organization. Journal of occupational psychology, 63(1), $1-18$. 
Allen, N. J., \& Meyer, J. P. (1993). Organizational commitment: evidence of career stage effects?. Journal of business research, 26(1), 49-61.

Allen, N. J., \& Meyer, J. P. (1996). Affective, continuance, and normative commitment to the organization: An examination of construct validity. Journal of vocational behavior, 49(3), 252-276.

Allen, N. J., \& Meyer, J. P. (2000). Construct validation in organizational behavior research: The case of organizational commitment. In Problems and solutions in human assessment (pp. 285-314). Springer, Boston, MA.

Analisa, Y., \& Wahyudi, S. (2011). pengaruh ukuran perusahaan, leverage, profitabilitas dan kebijakan dividen terhadap nilai perusahaan (studi pada perusahaan manufaktur yang terdaftar di bursa efek indonesia tahun 2006-2008) (Doctoral dissertation, Universitas Diponegoro).

Armstrong, Mi. (2006). A Handbook of Human Resource Practice (10th Edition). Bandung : Kogan Page Publisher.

Ashar, H., \& Lane-Maher, M. (2004). Success and spirituality in the new business paradigm. Journal of management inquiry, 13(3), 249-260.

Ashforth, B., \& Pratt, M. (2003). Institutionalized spirituality an oxymoron: The Handbook of Workplace Spirituality and Organizational Performance,(pp. 93-107). Armonk, NY: ME Sharpe.

Ashmos, D. P., \& Duchon, D. (2000). Spirituality at work: A conceptualization and measure. Journal of management inquiry, 9(2), 134-145.

Curtis, S., \& Wright, D. (2001). Retaining employees-the fast track to commitment. Management research news, 24.

Dessler, G. (2000). Human Resource Management 8th edition, New Jersey: Prentice Hall, Inc

Duchon, D., \& Plowman, D. A. (2005). Nurturing the spirit at work: Impact on work unit performance. The leadership quarterly, 16(5), 807-833.

Durkin, M., \& Bennett, H. (1999). Employee commitment in retail banking: identifying and exploring hidden dangers. International Journal of Bank Marketing, 17(3), 124-134.

Farzaneh, J., Farashah, A. D., \& Kazemi, M. (2014). The impact of person-job fit and personorganization fit on OCB. Personnel Review.

Ghozali, I. (2009). Aplikasi Analisis Multivariate dengan Program SPSS. Edisi Keempat. Semarang: Badan Penerbit Universitas Diponegoro.

Giacalone, R. A., \& Jurkiewicz, C. L. (Eds.). (2003). Handbook of workplace spirituality and organizational performance. Me Sharpe.

Griffeth, R. W., Hom, P. W., \& Gaertner, S. (2000). A meta-analysis of antecedents and correlates of employee turnover: Update, moderator tests, and research implications for the next millennium. Journal of management, 26(3), 463-488.

Gupta, M., Singh, M. G., \& Kumar, V. G. (2016). Spirituality at workplace and its relationship with job satisfaction-a study on public and private insurance sector in Punjab (Doctoral dissertation).

Handoko, T. H. (1994). Manajemen Personalia dan Sumber Daya Manusia, BPFE, Yogyakarta 
Hasibuan, M. (2000). Manajemen Sumber Daya Manusia. Edisi Revisi. Jakarta: PT. Bumi Aksara.

Hasibuan, M. (2007). Manajemen Dasar, Pengertian, dan Masalah. Cetakan Kesepuluh. PT. Bumi Aksara.

Hayati, N. R. (2014). Komitmen Organisasional: Definisi, Antecedents, dan Isu-Isu Penelitian. Jurnal Manajemen Bisnis, 5(1), 112-127.

Hom, P. W., Griffeth, R. W., Palich, L. E., \& Bracker, J. S. (1999). Revisiting met expectations as a reason why realistic job previews work. Personnel psychology, 52(1), 97-112.

Ibrahim, M., \& Mubarak, M. H. (2016). Budaya Etika, Niat untuk Bertahan dalam Organisasi dan Kesesuaian Individu dengan Organisasi Sebagai Mediator (Studi pada PT Garuda Indonesia Medan). Jurnal Ekonomi Manajemen dan Akuntansi (JEMSI), 2(1).

Judge, T. A., \& Cable, D. M. (1997). Applicant personality, organizational culture, and organization attraction. Personnel Psychology, 50(2), 359-393.

Judge, W.Q. (1999), The Leader's Shadow: Exploring and Developing Executive Character, JosseyBass, Thousand Oaks, CA.

Lawrence, A., \& Lawrence, P. (2009). Values, congruence and organizational commitment: PO fit in higher education institutions. Journal of Academic Ethics, 7(4), 297-314.

Leng, G. E., \& Chin, M. L. C. (2016). Person-job fit, personality, organizational commitment and intention to stay among employees in marketing departments. Jurnal Psikologi Malaysia, 30(1), 80-89.

Luthans, F. (2002). Organizational Behavior, 9th Edition. McGraw-Hill Inc., New York.

Luthans, F. (2006). Organization Behavior. Englewood Cliff, New Jersy: Prentice-Hall, Inc

Meyer, J. P., \& Allen, N. J. (1991). A three-component conceptualization of organizational commitment. Human resource management review, 1(1), 61-89.

Meyer, J. P., \& Allen, N. J. (1997). Commitment in the Workplace: Theory, Research, and Application, Sage, Thousand Oaks, CA.

Meyer, J. P., \& Herscovitch, L. (2001). Commitment in the workplace: Toward a general model. Human resource management review, 11(3), 299-326.

Milliman, J., Czaplewski, A. J., \& Ferguson, J. (2003). Workplace spirituality and employee work attitudes: An exploratory empirical assessment. Journal of organizational change management, 16(4), 426-447.

Milliman, J., Ferguson, J., Trickett, D., \& Condemi, B. (1999). Spirit and community at Southwest Airlines. Journal of organizational change management, 12(3).

Milliman, J., Gatling, A., \& Kim, J. S. (2018). The effect of workplace spirituality on hospitality employee engagement, intention to stay, and service delivery. Journal of Hospitality and Tourism Management, 35, 56-65.

Mowday, R, Porter L.W., \& Steers R.M.. (1982). Employee Organization Lingkages: the psycology of commitment, absenteism and turnover. San Diego: Academic Press.

Mowday, R. T., Steers, R. M., \& Porter, L. W. (1979). The measurement of organizational commitment. Journal of Vocational Behavior, 14(2), 224-247. 
Nurtjahjani, H. (2010). Spiritualitas kerja sebagai ekspresi keinginan diri karyawan untuk mencari makna dan tujuan hidup dalam organisasi. Jurnal Psikologi, 7(1), 27-30.

Pawar, B. S. (2016). Workplace spirituality and employee well-being: An empirical examination. Employee Relations, 38(6), 975-994.

Podsakoff, P. M., \& Organ, D. W. (1986). Self-reports in organizational research: Problems and prospects. Journal of management, 12(4), 531-544.

Podsakoff, P. M., Williams, L. J., \& Todor, W. D. (1986). Effects of organizational formalization on alienation among professionals and nonprofessionals. Academy of Management Journal, 29(4), 820-831.

Porter, L. W., \& Steers, R. M. (1973). Organizational, work, and personal factors in employee turnover and absenteeism. Psychological bulletin, 80(2), 151.

Porter, L. W., Steers, R. M., Mowday, R. T., \& Boulian, P. V. (1974). Organizational commitment, job satisfaction, and turnover among psychiatric technicians. Journal of applied psychology, 59(5), 603.

Price, J. L., \& Mueller, C. W. (1986). Absenteeism and turnover of hospital employees. JAI press.

Rego, A., \& e Cunha, M. P. (2008). Workplace spirituality and organizational commitment: an empirical study. Journal of organizational change management, 21(1), 53-75.

Rego, A., \& Souto, S. (2004). Comprometimento organizacional em organizações autentizóticas: um estudo luso-brasileiro. Revista de Administração de Empresas, 44(3), 3043 .

Risdayanti, H. (2014). Pengaruh pelayanan customer service terhadap kepuasan nasabah pada bank BRI Syariah Sungguminasa. Jurnal Aplikasi Manajemen, 14(4), 18-25.

Robbins, \& Coulter. (2003). Management (7th ed.): Prentice-Hall, Englewood Cliffs, NJ

Robbins, S. P. (1993). Organization Behavior: Consept, Convensus, \& Application, Prelince Hall. Ind. Inc.

Robbins, S. P., \& Judge, T. A. (2011). Organizational behaviour. New Jersey, USA: Pearson

Sedarmayanti. (2007). Good Governance dan Good Corporate Governance, Bagian Ketiga. CV. Mandar Maju.

Siahaan, Y. F. (2014). Pengaruh Human Resources Management Practice terhadap Employee Intention to Stay pada PT Media Nusantara Informasi (SINDO). Jurnal Manajemen, 11(2), 155-170.

Smeenk, S. G., Eisinga, R. N., Teelken, J. C., \& Doorewaard, J. A. C. M. (2006). The effects of HRM practices and antecedents on organizational commitment among university employees. The International Journal of Human Resource Management, 17(12), 2035-2054.

Solichin, M. R. (2019). Pengaruh Work Place Spirituality, Person Job Fit, dan Leadership Style terhadap Intention to Stay Perawat Rumah Sakit PKU Muhammadiyah Sruweng. Jurnal Ekonomi dan Teknik Informatika, 7(2), 21-32.

Steers, R. M. (1977). Antecedents and outcomes of organizational commitment. Administrative science quarterly, 46-56.

Sugiyono. (2009). Metode Penelitian Kuantitatif, Kualitatif, dan RED. Bandung: Alfabeta. 
Sugiyono. (2010). Metode Penelitian Kuantitatif, Kualitatif, dan RED. Bandung: Alfabeta.

Sugiyono. (2016). Metode Penelitian Kuantitatif, Kualitatif, dan Kombinasi (Mixed Methods). Bandung: Alfabeta.

Tepeci, M. (2001). The effect of personal values, organizational culture, and personorganization fit on individual outcomes in the restaurant industry.

Tsui, A. S., Pearce, J. L., Porter, L. W., \& Tripoli, A. M. (1997). Alternative approaches to the employee-organization relationship: does investment in employees pay off?. Academy of Management journal, 40(5), 1089-1121.

Widyawati, F. (2013). Pengaruh Keadilan Distributif Dan Career Plateau Terhadap Kepuasan Kerja Serta Dampaknya Pada Intention To Stay (Studi Pada PT X) (Doctoral dissertation, Diponegoro University).

Zhang, H., \& Agarwal, N. C. (2009). The mediating roles of organizational justice on the relationships between HR practices and workplace outcomes: an investigation in China. The International Journal of Human Resource Management, 20(3), 676-693.

Zurnali, C., \& Nadeak, W. (2010). Learning organization, competency, organizational commitment, and customer orientation: knowledge worker: kerangka riset manajemen sumber daya manusia masa depan. Unpad Press. 